\title{
Inter-Individual Differences in Ornamental Colouration in a Mediterranean Lizard in Relation to Altitude, Season, Sex, Age, and Body Traits
}

\author{
Gregorio Moreno-Rueda ${ }^{1}{ }^{\oplus}$, Senda Reguera ${ }^{1}$, Francisco J. Zamora-Camacho ${ }^{2}$ and Mar Comas ${ }^{1, *}$ \\ 1 Departamento de Zoología, Facultad de Ciencias, Universidad de Granada, E-18071 Granada, Spain; \\ gmr@ugr.es (G.M.-R.); sendareguera@gmail.com (S.R.) \\ 2 Departamento de Biodiversidad, Ecología y Evolución, Facultad de Ciencias Biológicas, \\ Universidad Complutense de Madrid, E-28040 Madrid, Spain; zamcam@ugr.es \\ * Correspondence: marcomas@ugr.es
}

check for updates

Citation: Moreno-Rueda, G.;

Reguera, S.; Zamora-Camacho, F.J.;

Comas, M. Inter-Individual

Differences in Ornamental

Colouration in a Mediterranean Lizard in Relation to Altitude, Season, Sex, Age, and Body Traits. Diversity 2021, 13, 158. https://doi.org/ 10.3390/d13040158

Academic Editor: Luc Legal

Received: 8 March 2021

Accepted: 5 April 2021

Published: 6 April 2021

Publisher's Note: MDPI stays neutral with regard to jurisdictional claims in published maps and institutional affiliations.

Copyright: (c) 2021 by the authors. Licensee MDPI, Basel, Switzerland. This article is an open access article distributed under the terms and conditions of the Creative Commons Attribution (CC BY) license (https:/ / creativecommons.org/licenses/by/ $4.0 /)$.

\begin{abstract}
Animals frequently show complex colour patterns involved in social communication, which attracts great interest in evolutionary and behavioural ecology. Most researchers interpret that each colour in animals with multiple patches may either signal a different bearer's trait or redundantly convey the same information. Colour signals, moreover, may vary geographically and according to bearer qualities. In this study, we analyse different sources of colour variation in the eastern clade of the lizard Psammodromus algirus. Sexual dichromatism markedly differs between clades; both possess lateral blue eyespots, but whereas males in the western populations display strikingly colourful orange-red throats during the breeding season, eastern lizards only show some commissure pigmentation and light yellow throats. We analyse how different colour traits (commissure and throat colouration, and the number of blue eyespots) vary according to body size, head size (an indicator of fighting ability), and sex along an elevational gradient. Our findings show that blue eyespots function independently from colour patches in the commissure and throat, which were interrelated. Males had more eyespots and orange commissures (which were yellow or colourless in females). Throat colour saturation and the presence of coloured commissures increased in older lizards. The number of eyespots, presence of a coloured commissure, and throat colour saturation positively related to head size. However, while the number of eyespots was maximal at lowlands, throat colour saturation increased with altitude. Overall, our results suggest that this lizard harbours several colour signals, which altitudinally differ in their importance, but generally provide redundant information. The relevance of each signal may depend on the context. For example, all signals indicate head size, but commissure colouration may work well at a short distance and when the lizard opens the mouth, while both throat and eyespots might work better at long distance. Meanwhile, throat colouration and eyespots probably work better in different light conditions, which might explain the altitudinal variation in the relative importance of each colour component.
\end{abstract}

Keywords: colouration; social signals; Psammodromus algirus; lizards; altitudinal gradient

\section{Introduction}

Colour ornaments are frequent in the animal kingdom, typically involved in social communication [1]. However, understanding the evolution of colour patterns in animals is challenging because it often arises from the interaction of concomitant selective pressures. Sexual selection favours sexual dichromatism and colourful patterns [2], whereas natural selection selects for dull and cryptic colourations [3]. Besides, animals frequently show complex and contrasting colour patterns consisting of multiple colour patches [4]. Multiple ornamental colour patches within individuals may be the result of different selective pressures on each patch $[5,6]$, and so each component of colouration may be related to different individual traits (multiple message hypothesis; e.g., [7-9]). Alternatively, different 
colour patches may act as redundant signals providing similar information, in this way increasing the reliability of the signal (backup hypothesis, [10,11]).

In reptiles, colouration is the result of a mix of pigments (carotenoids, pterins, and melanin) and structural layers including crystalline platelets [12]. In lizards, the size and spectral characteristics of colour patches have been related to different traits [13]. For example, different characteristics of colour patches can reflect fighting ability [14-16], as well as reproductive status in both females [17-19] and males [20-22], among several other traits.

Understanding the processes that generate intraspecific phenotypic variation is essential in evolutionary ecology. Colouration may vary geographically if selective pressures also vary [23-25]. In this sense, elevational gradients offer a valuable study framework encompassing a considerable environmental variation in a relatively short spatial range [26]. For example, Badyaev [27] described an elevational pattern in birds, in which the strength of sexual selection on colouration decreased with altitude. Badyaev [27] proposed several explanations for this pattern, some of which apply only to species with prolonged parental care. However, it is unknown whether such a pattern is also applicable to reptiles, studies on lizards providing mixed results [28-32].

In the present study, we investigated several sources of inter-individual variation in social colouration of the Mediterranean lizard Psammodromus algirus in Sierra Nevada Mountain (Spain). Psammodromus algirus is a medium-large lacertid (53-80 mm snoutvent length, SVL, in our study area) that inhabits shrubby habitats in the Mediterranean region of western North Africa, the Iberian Peninsula, and southern France [33]. In the Iberian Peninsula, this species is split into two phylogeographic clades [34], which differ in male colouration during the breeding season (see Figures 1 and 2 in [33]). In the western clade, adult males typically show orange-red colour on the head and throat during the breeding season [19,30,35-37], while young males only exhibit an orange spot in their mouth commissures [38]. These colour patches are absent in females. Meanwhile, social colouration in the eastern clade has been much less studied. In the eastern clade, adult males present an orange spot in their mouth commissures, but not orange colouration in the head and throat [39], just like young males in the western clade. Both adult males and females may exhibit a yellow patch on their throats during the breeding season [39]. Besides, $P$. algirus from both clades display a variable number of blue-ultraviolet eyespots in their flanks, which are more numerous in males than in females, and show little seasonal variation $[39,40]$.

The aim of this study is to examine the sources of inter-individual variation in the colour variables involved in social communication of a southern population within the eastern clade of $P$. algirus. We were interested in the diversity of colour patches in this species and its marked geographical variation. We related several colour traits (throat lightness, chroma, and hue, commissure colour and patch size, and the number of flank eyespots) with:

(1) Morphometric traits (SVL, body mass, and head size). Lizard morphometric traits strongly correlate with fitness. Body size is positively related to reproductive success in males [35,37,41] and females [42]. Head size is typically related to bite force, representing fighting ability, so it is related to social dominance in P. algirus [37]. While it is well known that head breeding colouration (orange) indicates body size and fighting ability in the western clade $[35,37,41]$, intervening in communication during agonist encounters, whether that is also the case of colour patterns in the eastern clade remains poorly understood.

(2) Sex. Albeit well reported in the western clade [35,36], sexual dichromatism is understudied in eastern populations (but see [39]). Some degree of dichromatism is expected given that sexual selection is typically stronger in males, especially in polygynous species [2]. While the mating system in the eastern clade is unknown, lizards from the western clade are polygynous; a male's territory overlaps with those of several females $[35,37]$. 
(3) Age. In the western clade, adult males are well differentiated from immature males by head colouration, but how colouration patterns vary with the advances of years is still unknown. In fact, in the western clade, it is well-determined that male head colouration varies with body size [35]. However, given that lizards are indeterminate growers, body size increases with age, so it is unclear whether colour signals indicate body size or age in this lizard. Males indicating old age may be preferred by females as their signals would indicate longevity and hence individual quality [43].

(4) Altitude. We examine how social colouration varies with altitude along a 2200-m elevational gradient. In a population of the western clade, lizards from localities separated $650 \mathrm{~m}$ in altitude differed in colouration, low-elevation individuals having more saturated colour in throats and more eyespots than high-elevation conspecifics [29,30]. However, whether colouration in populations from the eastern clade similarly varies with altitude remains unknown.

(5) Season. In the western clade, some signals as head and throat patch size and colouration vary seasonally [35], while others as the number of eyespots do not [40]. Seasonal variation in colouration of the eastern clade is poorly known (but see [39]).

Our final goal is to add to the knowledge of the evolution of lizard colouration. Concretely, our main purposes are to understand whether such a variety of signals provide different information on lizard quality or well provide redundant information, as well as to give insights on the sources of geographic variation in social colouration.

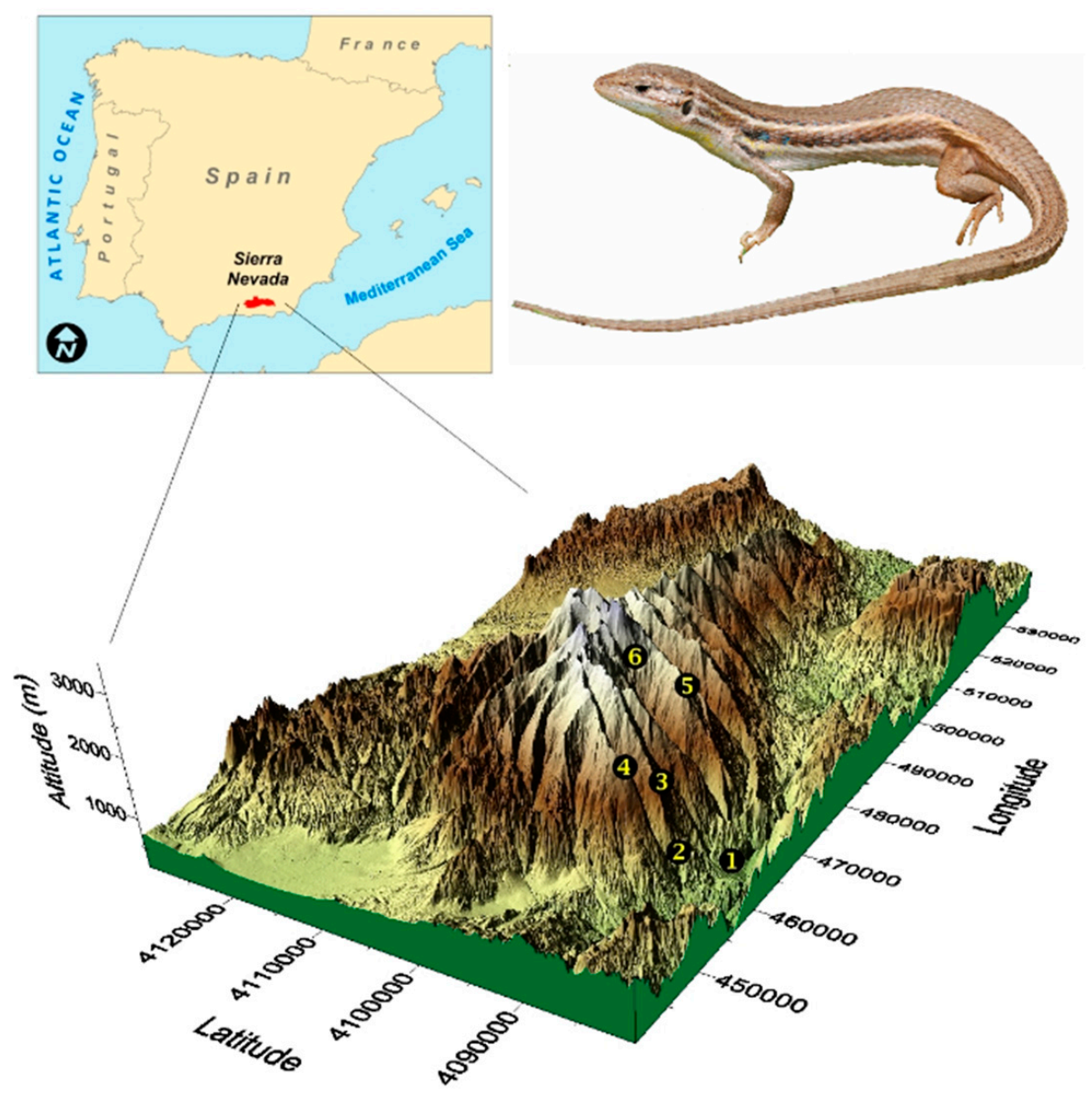

Figure 1. The three-dimensional map (bottom panel) is a representation of the Sierra Nevada Mountain and displays the location of the six sites sampled during this study along the elevational gradient: 300 (1), 700 (2), 1200 (3), 1700 (4), 2200 (5), and 2500 (6) m asl. The location of Sierra Nevada in the Iberian Peninsula (top, left) and an image of the lizard (top, right) are also shown. 


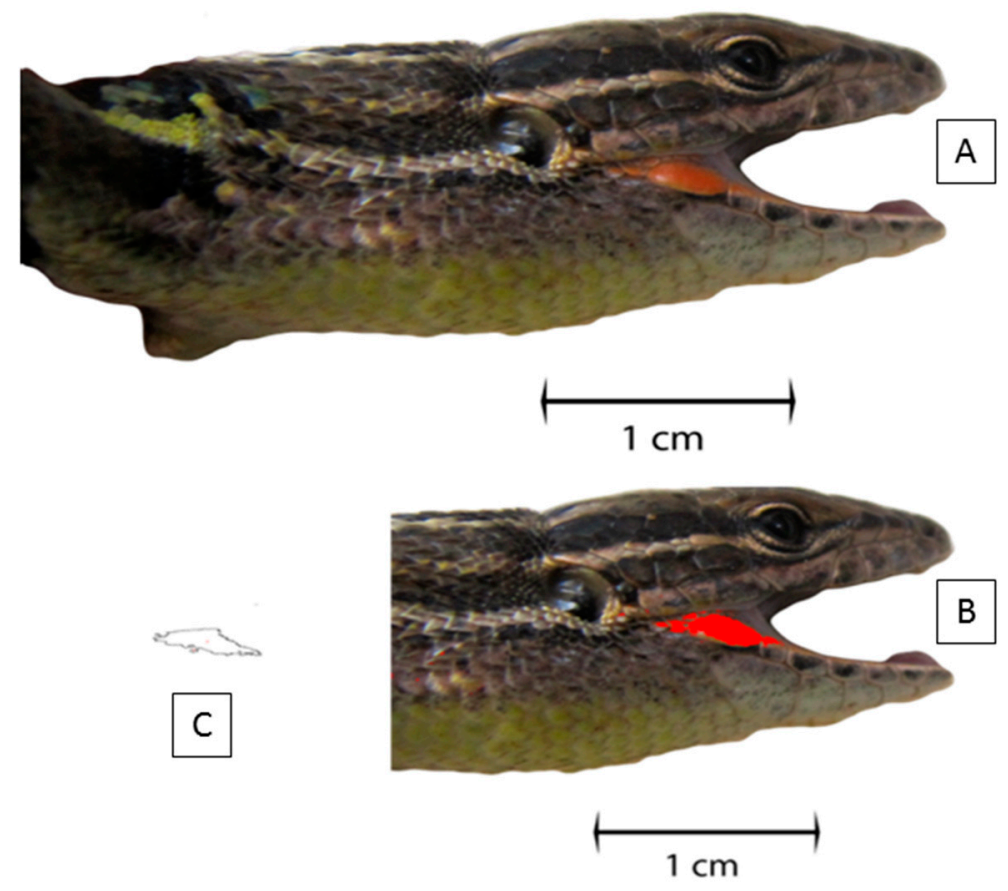

Figure 2. Representation of procedures for quantifying the coloured commissure area, using the software Image J (version 1.60). (A) First, we performed lateral photographs of the lizard with the mouth opens; (B) Second, we selected the coloured area with the "Colour threshold" tool; (C) Third, we measured the area with the "Analyse particles" tool.

\section{Material and Methods}

\subsection{Sampling and General Procedures}

Fieldwork was performed in the Sierra Nevada mountain system (SE Spain), where P. algirus inhabits from 200 to $2800 \mathrm{~m}$ asl, with permission of the Andalusian government and National Park of Sierra Nevada (references GMN/GyB/JMIF and ENSN/JSG/JEGT/MCF). We sampled six localities sited at 300, 700, 1200, 1700, 2200, and $2500 \mathrm{~m}$ asl (Figure 1) with a similar structure of vegetation (more details in [44]). Lizards were captured by hand and transported to the lab in cotton bags. Sampling occurred during their activity season in Sierra Nevada, spanning from March to September [44], during the years 2010-2013. We captured 482 adult lizards (males/females per year, 2010: 43।58, 2011: 49 I50, 2012: 65 |60, 2013: 82 |75). We measured their SVL with a metal ruler (accuracy $1 \mathrm{~mm}$ ), body mass with a digital scale (accuracy $0.01 \mathrm{~g}$ ) and head width with a digital calliper (accuracy $0.01 \mathrm{~mm}$ ). Sex was determined according to femoral-pore development (more developed in males [29]). Only adults were considered because we were interested in inter- and intra-sexual communication. Given that SVL did not differ between sexes in our study area [45], we considered adults lizards with the minimum body size for which we found gravid females. Notice that body size varies with altitude [45], so this minimum SVL was estimated for each altitude (at $300 \mathrm{~m}: 53 \mathrm{~mm}$; $700-1700 \mathrm{~m}$ : $55 \mathrm{~mm} ; 2200 \mathrm{~m}: 62 \mathrm{~mm} ; 2500 \mathrm{~m}$ : $63 \mathrm{~mm}$ ). Because lizards were part of a long-term study, they were marked by toe clipping and resampled lizards $(\sim 5 \%)$ were excluded to avoid pseudoreplication. Toe clipping is frequently used to mark lizards with little impact on welfare and survival [46]. Toes of a subsample $(n=118)$ were conserved in ethanol and used for age determination using phalanx skeletochronology (detailed methods in [47]). Skeletochronology was a technique widely used to estimate age in reptiles (at the accuracy of a year), which has proven to be very accurate [48].

\subsection{Quantification of Colour Patches}

Along the four years of the study, we measured throat (gular region) colour with a colourimeter (Minolta CM-2600d). The colourimeter, placed on the lizard's skin, projected 
three beams of light through a 3-mm-diameter hole. As a result, it took three measures of reflectance and automatically gave the average of each colour component [49]. These components correspond to the $\mathrm{L}^{*} \mathrm{a}^{*} \mathrm{~b}^{*}$ colour-space of the Commission Internationale $d^{\prime}$ Eclairage (CIE 1976 [50]). The device measured the reflectance of the surface on the spectrum of light of the visible range, from 400 to $700 \mathrm{~nm}$ wavelengths. We did not study skin reflectance in the ultra-violet (UV) range of the spectrum because the throat has no reflectance peak in the UV range. $L^{*} a^{*} b^{*}$ colour space is a 3-dimensional rectangular colour space. $L^{*}$ axis represents lightness ( 0 is black, 100 is white); $a^{*}$ axis represents red-green gradient (positive values are red, negative values are green); $b^{*}$ axis represents blue-yellow gradient (positive values are yellow, negative values are blue). From $L^{*} a^{*} b^{*}$ values we determined chroma (saturation or purity) as $C^{*}=\left[\left(\mathrm{a}^{*}\right)^{2}+\left(\mathrm{b}^{*}\right)^{2}\right]^{1 / 2}$ (measured as the percentage distance from the centre [0] of the colour space to its circumference [100] where pure spectral colours are represented); and hue angle (the "colour" in common parlance) as $\mathrm{H}^{*}=\tan ^{-1}\left(\mathrm{~b}^{*} / \mathrm{a}^{*}\right)$ [51].

In 2011-2013, we additionally recorded the presence or absence, and colour (orange or yellow) if present, of a patch in the mouth commissures, and counted the total number of blue eyespots in the lizard flanks. For those lizards presenting a well-differentiated colour patch in commissures, we took photographs from the right side of the head (consistently with the mouth open; Figure 2). We used a Canon Power Shot SX200 IS digital camera and a graph paper background for size reference. Then, we measured the area of this pigmented patch using the software Image J (version 1.60 [52]). First, we scaled the photos using the graph paper (in $\mathrm{mm}$ ) and the "Set scale" tool. Then, we adjusted the area of the patch using the "Colour threshold" tool. We afterwards measured the area of each coloured patch with the "Analyse particles" tool (Figure 2). The software measured all the patches delineated and gave the total selected area in $\mathrm{mm}^{2}$.

\subsection{Statistical Analyses}

Sample sizes differed among the variables measured (Appendix A). Eyespot number and commissure colour and size were not recorded in 2010. The size of the commissure patch was measured only in lizards in which it was present (50\% of lizards). Age was estimated in a random subsample of 118 lizards. For diverse reasons, some data for different variables were lost in several individuals. The fact that not all variables were available in every individual conditioned the statistical analyses we could perform minimising the loss of sample size.

Firstly, we checked for possible outliers in every variable by using Cleveland plots [53]. Secondly, we graphically checked the normality and homoscedasticity of the variables [53]. Throat hue and area of the commissure were log-transformed to match these assumptions. Throat lightness was arcsin-transformed. SVL, body mass and head width were logtransformed to meet homoscedasticity and linearity [54]. Throat chroma and the number of eyespots were not transformed. Although all analyses were carried out with the variables transformed, raw data are shown in graphics and when providing mean values (with SE).

The colour variables measured (number of eyespots, throat lightness, throat chroma, throat hue, presence and colour of commissure patch, and area of the commissure patch) may not be independent among themselves. For this reason, in a first analysis, we examined the bivariate Pearson product-moment correlation between continuous variables, and we tested with Anova whether the value of the colour variables differed among categories of commissure colour (colourless, orange, yellow).

In a second analysis, we carried out a linear model for every colour variable with a continuous distribution, and a multinomial model linked to a logit function for commissure colour. In these models, the predictor variables were SVL, body mass, head width (all log-transformed, continuous), altitude (six levels: 300, 700, 1200, 1700, 2200, $2500 \mathrm{~m}$ ), season (date when lizards were captured, arranged into three categories: March-May, June-July, August-September), sex (males, females), and year (2010, 2011, 2012, 2013; data for 2010 only available for throat lightness, chroma, and hue). All analyses were carried out with 
R 3.6.1 [55]. Multinomial models were performed using the function "multinom" of the package "nnet" v. 7.3-14 [56]. In addition, we applied a model selection approach based on the Akaike Information Criterion (AIC) with the "MuMIn" package [57]. In this analysis, models with a value of $\triangle \mathrm{AIC}$ less than 2 were chosen [58]. Moreover, given that some colour variables showed some correlation (see below), we repeated the best models including the other variables of colouration as covariates to check the soundness of the findings. Normality and homoscedasticity of every model's residuals were checked [53]. Only significant effects supported by the three statistical approaches (full model, model selection, and best models controlling for other colour variables) were considered as sound. We also checked for interactions between the predictor variables. However, most interactions were non-significant or lacked soundness, so we decided not to show them for the sake of clarity.

Lastly, lacertid lizards typically have indeterminate growth. Consequently, older lizards are also larger. In this way, age and body size may be confounded. To test the effect of age, we repeated the analyses with a subsample of known-age individuals, by including the age estimated with skeletochronology in the models. Given that these models included SVL and age, the effect of the two variables can be disentangled.

\section{Results}

\subsection{Relationship among Colour Parameters}

The number of blue eyespots was unrelated to the other colouration variables (throat chroma, lightness and hue, and area of the commissure), but lizards with orange commissures had significantly more eyespots $\left(F_{2,271}=31.54, p<0.001\right.$; Table 1$)$. This finding seems to be linked to the fact that males have more eyespots and a higher probability to present orange commissures (see below). Indeed, when sex was introduced as a predictor, the relationship between number of eyespots and colour of commissures disappeared $\left(F_{2,270}=1.49, p=0.23\right.$; effect of sex: $\left.F_{1,270}=39.15, p<0.001\right)$. Meanwhile, throat colouration parameters were interrelated; chroma and lightness were negatively correlated, while hue was positively correlated with lightness and so negatively related to chroma (Table 1). Nonetheless, correlation coefficients were relatively low $(|r| \leq 0.51)$. The size of commissure patch was positively correlated with throat chroma, and negatively with hue and lightness (Table 1). In addition, individuals with a commissure patch (orange or yellow) had more saturated throats $\left(F_{2,274}=23.31, p<0.001\right.$; Table 1$)$. The reverse occurred for throat lightness $\left(F_{2,274}=17.96, p<0.001\right.$; Table 1$)$. Throat hue was unrelated to commissure colour $\left(F_{2,274}=0.24, p=0.79\right)$. Lizards with orange commissures tended to have larger commissure patches than lizards with yellow commissures $(0.74 \pm 0.07$ vs. $0.48 \pm 0.16 \mathrm{~mm}^{2} ; F_{1,111}=3.14, p=0.079$ ). Therefore, mouth commissure and throat colourations were seemingly interrelated.

\subsection{Correlates of Colouration}

The full model (Table 2) showed that the number of eyespots was maximal at a low elevation and minimal at mid-elevation (Figure 3a). Males had more eyespots than females (Figure 3b). Moreover, lizards with larger heads showed more eyespots (Figure 3c). The number of eyespots did not significantly vary with season or body size (SVL or mass). According to a model selection approach, the best model was that including altitude, sex, and head size (Table 3). The second-best model included those variables plus SVL $(\triangle \mathrm{AIC}=1.79)$, which, however, failed to significantly explain variation in the number of eyespots.

Throat lightness significantly varied with altitude (Table 2). Concretely, lizards from localities at 2200 and $2500 \mathrm{~m}$ had darker throat than those from lower altitudes (Figure 4a). Lizard throat was darker at the end of the breeding season (Figure $4 \mathrm{~b}$ ). Lizards with larger SVL and heads showed darker throats than smaller lizards (Table 2; Figure 4c; data not shown for SVL). Besides, throat lightness varied among years (Table 2). The four best models $(\triangle \mathrm{AIC}<2)$ included altitude, season, year, and head size as predictors (Table 3 ). Given that throat lightness was correlated with throat chroma and hue, we repeated the 
best model including these two variables as predictors to control for them. The resulting model was qualitatively very similar to the best model (data not shown), with the exception that SVL was no longer significantly related to throat lightness. SVL was not included in the fourth best model (Table 3), so there was little support for this variable being related to throat lightness.

Throat chroma increased with altitude (Figure 5a) and decreased with the advance of the season (Figure 5b; Table 2). Throat chroma increased with SVL and head size (Figure 5c, data not shown for head size). Besides, throat chroma showed interannual variation (Table 2 ). With the model selection, three models had $\triangle \mathrm{AIC}<2$, all including altitude, season, year, SVL, and head size as significant predictors of throat chroma (Table 3). When controlling for throat lightness and hue, results were similar, but head size was no longer significant, and a marginally significant effect of body mass emerged (data not shown).

Table 1. Correlations among the continuous variables (provided sample size -in the subscript-, correlation coefficient and $p$-value are provided), and average values $( \pm \mathrm{SE})$ for each category of commissure colour (no colour, yellow, or orange). Sample sizes for each category of commissure colour between brackets (for eyespots of lizards with orange commissures, the sample size was 103). Raw data are shown, but statistical tests were carried out with transformed variables when necessary. In bold significant relationships or differences. Different superscripts indicate significant differences according to an unequal N HSD post hoc test.

\begin{tabular}{|c|c|c|c|c|c|c|c|}
\hline & \multicolumn{4}{|c|}{ Correlations } & \multicolumn{3}{|c|}{ Commissure Colour } \\
\hline & $\begin{array}{c}\text { Throat } \\
\text { Lightness }\end{array}$ & $\begin{array}{l}\text { Throat } \\
\text { Chroma }\end{array}$ & Throat Hue & $\begin{array}{c}\text { Commissure } \\
\text { Area }\end{array}$ & No (138) & Yellow (33) & Orange (106) \\
\hline Eyespots & $\begin{array}{c}r_{362}=0.02 \\
p=0.71\end{array}$ & $\begin{array}{c}r_{362}=0.03 \\
p=0.51\end{array}$ & $\begin{array}{c}r_{362}=0.08 \\
p=0.12\end{array}$ & $\begin{array}{c}r_{110}=0.04 \\
p=0.71\end{array}$ & $3.64^{\mathrm{a}} \pm 0.18$ & $3.85^{\mathrm{a}} \pm 0.44$ & $5.79^{b} \pm 0.20$ \\
\hline $\begin{array}{c}\text { Throat } \\
\text { Lightness }\end{array}$ & & $\begin{array}{c}r_{473}=-0.51 \\
p<0.001\end{array}$ & $\begin{array}{c}r_{473}=0.21 \\
p<0.001\end{array}$ & $\begin{array}{c}r_{114}=-0.30 \\
p<0.001\end{array}$ & $81.28^{a} \pm 0.37$ & $76.09^{b} \pm 1.12$ & $79.57^{c} \pm 0.44$ \\
\hline Throat Chroma & & & $\begin{array}{c}r_{473}=-0.13 \\
p=0.006\end{array}$ & $\begin{array}{c}r_{114}=0.46 \\
p<0.001\end{array}$ & $12.20^{a} \pm 0.36$ & $20.10^{b} \pm 1.58$ & $17.19^{b} \pm 0.92$ \\
\hline Throat Hue & & & & $\begin{aligned} r_{114} & =-0.18 \\
p & =0.06\end{aligned}$ & $88.86 \pm 1.09$ & $88.87 \pm 2.10$ & $87.70 \pm 1.08$ \\
\hline
\end{tabular}

Table 2. Full models for each colour variable. In bold, predictors with a significant effect. Degree of freedom (df) as well as $F$-value for lineal models and $\chi^{2}$ for multinomial model are shown. ${ }^{*} p<0.05,{ }^{* *} p<0.01,{ }^{* * *} p<0.001$.

\begin{tabular}{|c|c|c|c|c|c|c|c|c|c|c|}
\hline & & & \multicolumn{4}{|c|}{ Throat } & \multicolumn{4}{|c|}{ Commissure } \\
\hline & \multicolumn{2}{|c|}{ Eyespots } & \multirow[b]{2}{*}{ df } & \multirow{2}{*}{$\begin{array}{l}\text { Lightness } \\
\text { F-Value }\end{array}$} & \multirow{2}{*}{$\begin{array}{l}\text { Chroma } \\
\text { F-Value }\end{array}$} & \multirow{2}{*}{$\begin{array}{c}\text { Hue } \\
\text { F-Value }\end{array}$} & \multicolumn{2}{|c|}{ Colour } & \multicolumn{2}{|c|}{ Area } \\
\hline & Df & $F$-Value & & & & & df & $x^{2}$ & $\mathrm{df}$ & $F$-Value \\
\hline Altitude & 5,333 & $3.88^{* *}$ & 5,430 & $8.48 * * *$ & $3.25 * *$ & $6.12 * * *$ & 10 & 4.08 & 5,97 & 0.75 \\
\hline Season & 2,333 & 0.08 & 2,430 & $12.79 * * *$ & $10.93 * * *$ & $8.16 * * *$ & 4 & 10.38 * & 2,97 & $4.96^{* *}$ \\
\hline Year & 2,333 & 1.18 & 3,430 & $6.48 * * *$ & $5.93 * * *$ & $2.98 *$ & 4 & 1.92 & 2,97 & $6.58 * *$ \\
\hline Sex & 1,333 & $57.62 * * *$ & 1,430 & 2.98 & 0.73 & 1.77 & 2 & $90.72 * * *$ & 1,97 & 2.23 \\
\hline Mass & 1,333 & 0.71 & 1,430 & 0.99 & 2.83 & 0.31 & 2 & 0.99 & 1,97 & 2.67 \\
\hline SVL & 1,333 & 1.44 & 1,430 & $4.58 *$ & $8.50 * *$ & 1.12 & 2 & 0.73 & 1,97 & 1.66 \\
\hline Head & 1,333 & $6.78 *$ & 1,430 & $8.94 * *$ & $4.86 *$ & 1.12 & 2 & $8.99 *$ & 1,97 & 0.15 \\
\hline
\end{tabular}



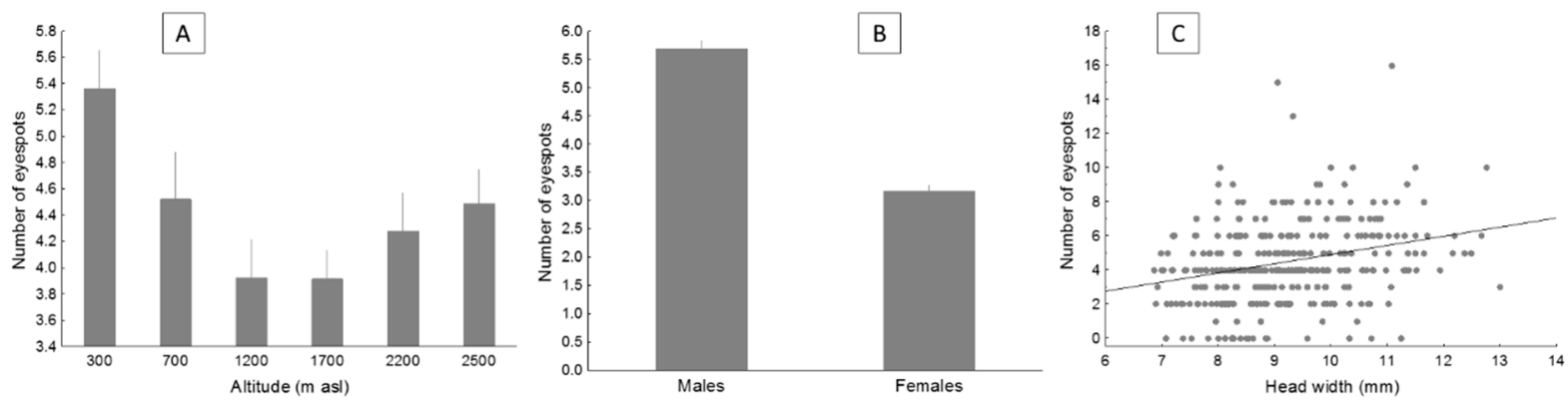

Figure 3. The average number of eyespots (with SE) in the flanks of the lizard P. algirus, according to altitude (A) and sex (B), and the relationship between the number of eyespots and head width (C). Notice that raw data are shown, but statistical analyses were performed with transformed data when necessary.

Table 3. Models chosen by model selection approach based on AIC. In bold, predictors with a significant effect.

\begin{tabular}{|c|c|c|c|c|c|}
\hline Dependent Variable & Predictors & df & $\mathrm{AICc}$ & $\Delta \mathrm{AIC}$ & Weight \\
\hline \multirow[t]{2}{*}{ Eyespots } & Altitude + Sex + Head & 9 & 1437.01 & 0 & 0.29 \\
\hline & Altitude + Sex + Head + SVL & 10 & 1438.80 & 1.79 & 0.12 \\
\hline \multirow[t]{4}{*}{ Throat Lightness } & Altitude + Season + Year + Head + SVL + Sex & 15 & -1161.73 & 0 & 0.31 \\
\hline & Altitude + Season + Year + Head + SVL + Sex + Mass & 16 & -1160.61 & 1.13 & 0.18 \\
\hline & Altitude + Season + Year + Head + SVL & 14 & -1160.28 & 1.45 & 0.15 \\
\hline & Altitude + Season + Year + Head + Sex & 14 & -1159.82 & 1.91 & 0.12 \\
\hline \multirow[t]{3}{*}{ Throat Chroma } & Altitude + Season + Year + Head + SVL + Mass & 15 & 2863.91 & 0 & 0.31 \\
\hline & Altitude + Season + Year + Head + SVL & 14 & 2864.35 & 0.45 & 0.25 \\
\hline & Altitude + Season + Year + Head + SVL + Mass + Sex & 16 & 2865.30 & 1.40 & 0.15 \\
\hline \multirow[t]{3}{*}{ Throat Hue } & Altitude + Season + Year + Sex & 13 & -648.44 & 0 & 0.25 \\
\hline & Altitude + Season + Year + Sex + Head & 14 & -646.98 & 1.46 & 0.12 \\
\hline & Altitude + Season + Year + Sex + Mass & 14 & -646.49 & 1.95 & 0.10 \\
\hline \multirow[t]{2}{*}{ Commissure Colour } & Season + Sex + Head + Mass & 12 & 272.67 & 0 & 0.41 \\
\hline & Season + Sex + Head + SVL & 12 & 273.09 & 0.42 & 0.33 \\
\hline \multirow[t]{8}{*}{ Commissure Area } & Year + Season + Mass + Head & 8 & 198.57 & 0 & 0.15 \\
\hline & Year + Season + Sex + Mass & 8 & 198.74 & 0.17 & 0.14 \\
\hline & Year + Season + Sex + SVL + Mass & 9 & 198.87 & 0.30 & 0.13 \\
\hline & Year + Season + SVL + Head & 8 & 199.25 & 0.68 & 0.11 \\
\hline & Year + Season + Sex + SVL & 8 & 199.75 & 1.18 & 0.08 \\
\hline & Year + Season + Sex + Mass + Head & 9 & 199.81 & 1.24 & 0.08 \\
\hline & Year + Season + SVL + Mass + Head & 9 & 200.13 & 1.55 & 0.07 \\
\hline & Year + Season + Sex + SVL + Head & 9 & 200.22 & 1.65 & 0.06 \\
\hline
\end{tabular}
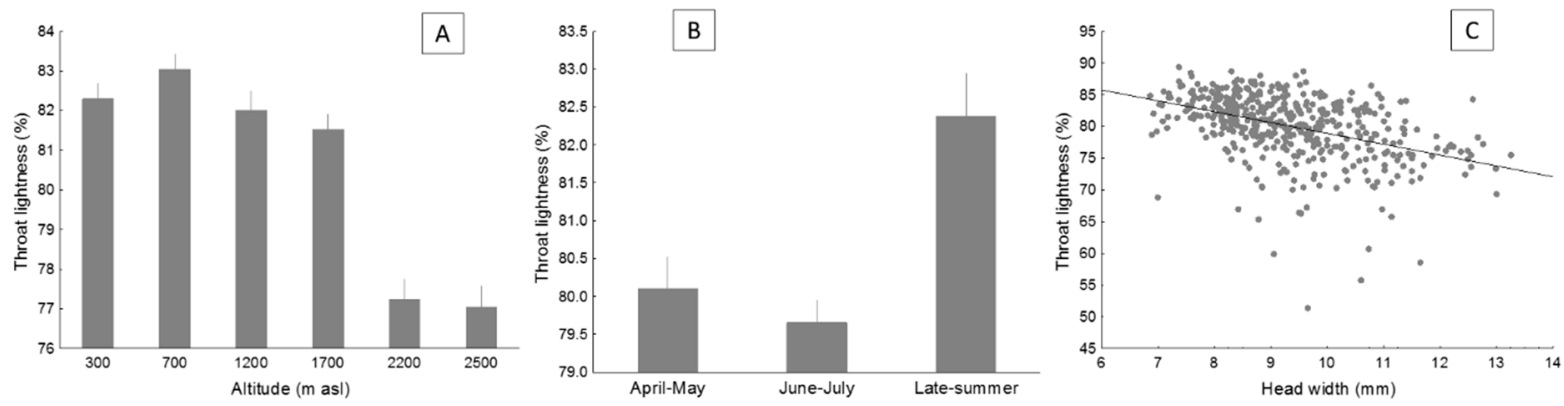

Figure 4. Average values of throat lightness (with SE) in the lizard P. algirus, according to altitude (A) and season (B), and the relationship between throat lightness and head width $(\mathbf{C})$. Notice that raw data are shown, but statistical analyses were performed with transformed data when necessary. 

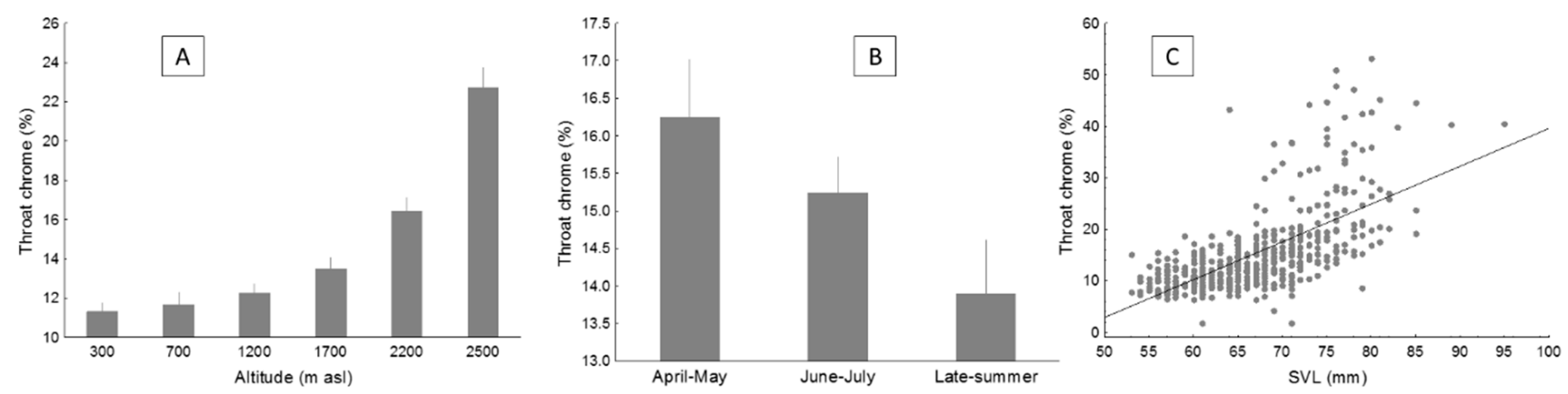

Figure 5. Average values of throat chroma (with SE) in the lizard P. algirus, according to altitude (A) and season (B), and the relationship between throat chroma and SVL $(\mathbf{C})$. Notice that raw data are shown, but statistical analyses were performed with transformed data when necessary.

According to the full model, throat hue showed covariation with altitude, season, and year, but not with sex or lizard morphology (Table 2). Throat hue tended to decrease with altitude and increased with the advance of the season (data not shown for simplicity). The model selection provided similar results, but, the best models also included sex, which significantly explained part of the variation in throat hue (Table 3). The inclusion of throat lightness and chroma in the model did not alter significantly the results (not shown).

The colour of the commissure differed between sexes, males usually having orange commissures, while females had yellow or no coloured commissure (Figure 6a; Table 2). The frequency of lizards with orange commissures decreased with the advance of the breeding season (Figure 6b; Table 2). Lastly, individuals with coloured commissure (either orange or yellow) had larger heads than individuals without commissure (Figure 6c, Table 2). No other variable was significantly related to commissure colour (Table 2). Model selection approach selected for two models including sex, season, and head size as significant predictors (Table 3).
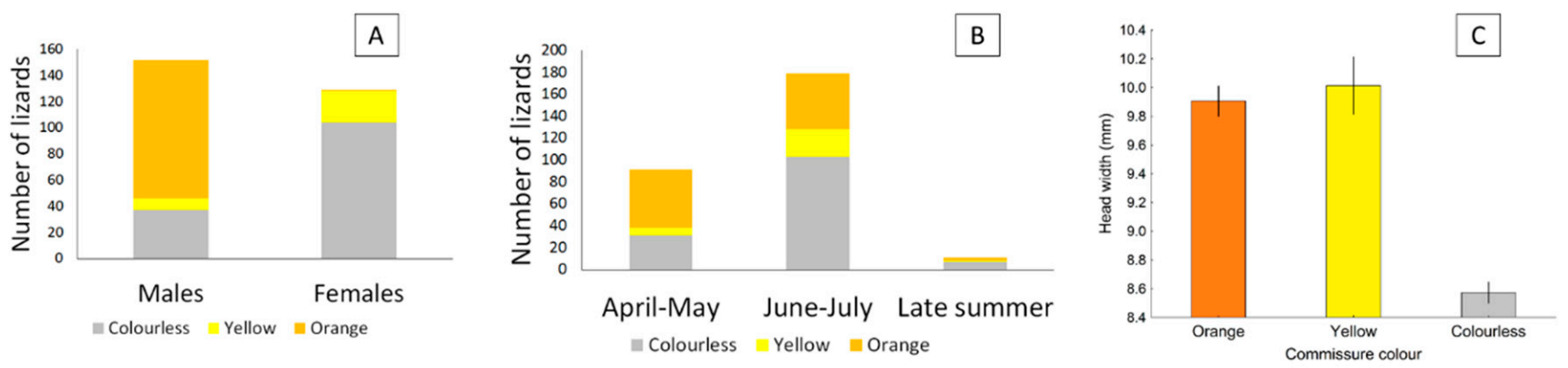

Figure 6. Frequency of P. algirus lizards with colourless, yellow or orange commissure according to sex (A) and season (B), and head width (with SE) of lizards according to commissure colour (C).

The area of the coloured commissure varied significantly with season and year (Table 2), tending to decrease with the advance of the breeding season (Figure 7). Eight models were selected by model selection. All models included season and year as significant predictors. No model included altitude. The remaining variables were included in five models, being significant in some, but not in others (Table 3). A model including throat lightness, chroma, and hue did not alter significantly these results (not shown).

\subsection{The Effect of Age}

As expected, SVL increased with age $\left(F_{4,113}=14.06, p<0.001\right.$; Appendix B). We found that older individuals were more likely to have coloured commissures $\left(\chi^{2}{ }_{6}=12.83\right.$, $p=0.046$; Figure 8a). Moreover, throat chroma increased with age (Figure $8 b$ ). This last result was confirmed by model selection. Two models were selected including the variables age + body mass $($ AICc $=678.33)$ and age + body mass + head size $($ AICc $=679.14)$. Notice 
that the two models included age, but not SVL, as a predictor of throat chroma. Previous analyses showed that throat chroma was the only colour variable that increased with SVL (Table 4). However, the present findings suggest that throat chroma is influenced by age rather than by body size.

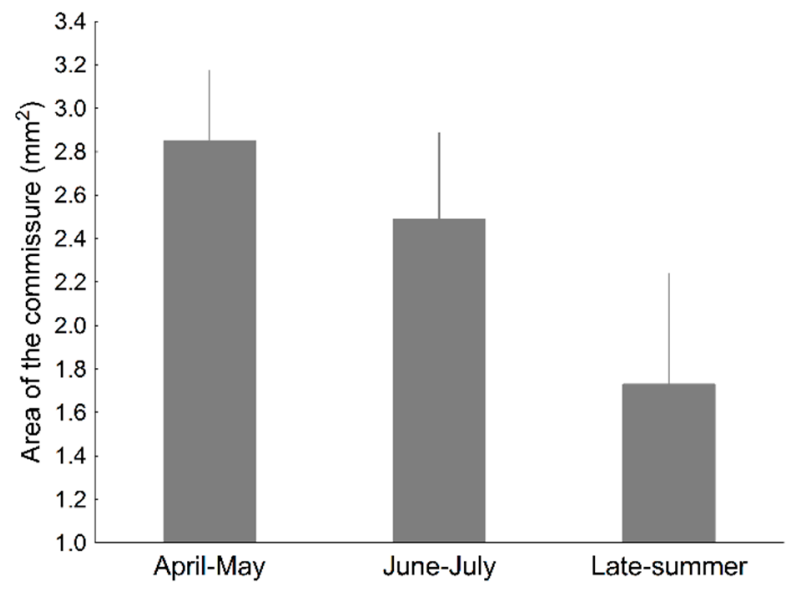

Figure 7. Average values of commissure area (with SE) in the lizard P. algirus, according to season.
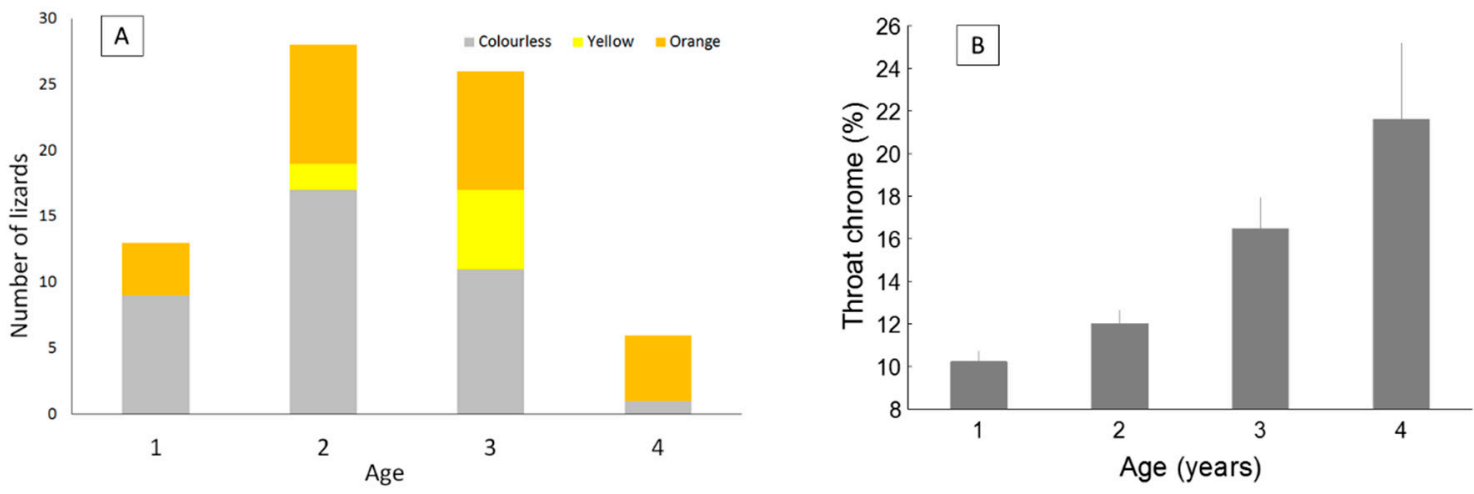

Figure 8. Frequency of lizards with colourless, yellow or orange commissure according to age (A) and average (with SE) throat chroma according to age (B).

Table 4. Summary of the main results. In bold are the clear results, whereas somewhat dubious results are not in bold.

\begin{tabular}{|c|c|c|c|c|c|c|c|}
\hline & Altitude & Season & Year & Sex & SVL & Mass & Head \\
\hline Eyespots & U-shaped & No & No & More in males & No & No & Increase \\
\hline Throat Lightness & $\begin{array}{c}\text { Darker at the } \\
\text { highest altitudes }\end{array}$ & $\begin{array}{c}\text { Lighter at the end of } \\
\text { the season }\end{array}$ & Yes & No & Decrease & No & Decrease \\
\hline Throat Chroma & Linear increase & Linear decrease & Yes & No & $\begin{array}{l}\text { Increase } \\
\text { (with age) }\end{array}$ & No & Increase \\
\hline Throat Hue & Decrease & Linear increase & Yes & Yes & No & No & No \\
\hline $\begin{array}{l}\text { Commissure } \\
\text { Colour }\end{array}$ & No & $\begin{array}{l}\text { Less orange lizards } \\
\text { with advanced } \\
\text { season }\end{array}$ & No & $\begin{array}{l}\text { Orange, males; yellow } \\
\text { or colourless, females }\end{array}$ & No & No & $\begin{array}{c}\text { Larger in } \\
\text { coloured lizards }\end{array}$ \\
\hline $\begin{array}{l}\text { Commissure } \\
\text { Area }\end{array}$ & No & Linear decrease & Yes & Larger in males & No & No & No \\
\hline
\end{tabular}

\section{Discussion}

Table 4 summarises the conclusions based on the main results. The findings in this study suggest that blue eyespots function independently from colour patches in the commissure and throat, while throat and commissure colouration were interrelated. Moreover, eyespots and both commissure and throat varied in different ways with altitude 
and season. Eyespots varied with altitude following a U-shaped pattern, while throat colour increased in saturation (chroma) with altitude. Also, throat colouration was darker in the highest elevations, where lizards are typically darker [59]. While eyespots were permanent colour patches (as in the western clade [40]), commissure and throat colouration varied with the season. At the beginning of the breeding season, we found more lizards with coloured commissures and throat colour was darker and more saturated. Similar findings were reported for a northern population of the same phylogenetic clade [39], which suggests that throat and commissure patches are involved in communication during breeding. Similarly, in the western clade, orange head colouration in adult males and coloured commissures in young males are present during the breeding season $[19,35,36,38]$.

We found some degree of sexual dichromatism; males typically had more eyespots and orange commissures (which were yellow or colourless in females). Hence, although sexual dichromatism was not as pronounced as in the western clade, a slight dichromatism is still present in the eastern clade. Throat saturation and the presence of coloured commissures was indicative of age. Meanwhile, the number of eyespots, presence of a coloured commissure, and throat saturation, all were indicators of head size, and thus of fighting ability. Therefore, although colour patches changed with altitude and season in different ways (probably reflecting different subjacent colour production costs and mechanisms and/or selective pressures), they seem, in general, to be redundant indicating the same traits of lizards: sex, fighting ability, and age. One possibility is that these signals are used in different contexts, indicating the same traits at different distances or in different light conditions.

\subsection{Colouration as Indicators of Fighting Ability, Sex, and Age}

All colour patches measured (eyespots, commissure and throat) seem indicators of head size (Table 4), which is known as a good indicator of fighting ability [60]. Lizards with greater fighting ability are more successful in defending their territories and hence obtain higher mating success [37]. Several studies suggest that blue-ultraviolet colouration, as that present in eyespots, is related to fighting ability $[16,61,62]$, but pigmentary colourations may also serve as indicators of fighting ability [63]. During a contest, signals correlated with fighting ability may help individuals to assess the relative competitive ability of rivals and so to avoid being involved in a costly physical combat [2]. To be informative, such signals should be honest indicators of fighting ability. Colouration may be a reliable indicator of fighting ability when maintained by social interactions [64]. Indeed, in the western clade of $P$. algirus, orange head colouration is a good indicator of social dominance, but orange-headed lizards are also more often involved in fighting, so subordinate lizards would pay a cost if vividly coloured [41]. Moreover, throat and commissure colouration might act as amplifiers of head size. This may be especially important in commissure colouration, which is displayed only when the mouth is open, hence allegedly showing the intention of biting and amplifying the perceived mouth size [65]. Furthermore, in the western clade, several costs have been associated with male nuptial colouration, such as reduced immune capacity, increased risk of ectoparasitism and ultimately reduced survival, which could serve to maintain honesty $[30,35,36]$.

While lizards from western populations are strongly dichromatic, sexual dichromatism in our study population was reduced to commissure colour (orange in males, yellow or colourless in females) and the number of eyespots (more numerous in males). Therefore, commissure colour seems to intervene in sex recognition. The fact that females display yellow throat and blue eyespots similarly to males suggests that females also use colour patches in social communication. Female lizards frequently display colour patches, usually related to receptiveness to breed [17-19]. However, alternative explanations, typically poorly explored, are possible. Females could use throat colouration (and yellow commissures) to indicate fighting ability to rivals. Females could also indicate some type of individual quality to potential mates [66]. However, colouration in females might simply be the result of correlated selection in males [67]. Anyway, the reduced sexual dichromatism 
in the eastern clade suggests that sexual selection on male traits is weaker in the eastern than in the western clade.

In Sierra Nevada, older individuals expressed both the yellow patch on the throat and the orange commissures more frequently than young lizards. Given that this is a trans-sectional study, we cannot disentangle whether colourful lizards lived longer (duller lizards selectively disappearing from the population as they aged), or lizards invested more in colouration as they aged. In either case, these colour patterns would indicate higher survival capability of the bearer. Younger lizards may be selected for concealment, mimicking females, hence not developing the yellow patch or the orange commissure until they grow large enough to compete with older males [38,41]. However, dominant males may detect female-mimicking males using chemosensorial cues [68]. Alternatively, colour cues indicating lizard age could be used to evaluate the survival prospects of potential mates [43]. In order for signals of survival ability to be honest, they should be costly to produce or maintain for their bearers [69]. For instance, in the western clade, conspicuous orange head colourations make individuals more visible to predators [70], so only high-quality lizards may survive older.

\subsection{Altitudinal Variation in Colouration}

We report that eyespots and throat colouration followed different altitudinal patterns; the number of blue eyespots was highest at low elevation and then followed a U-shaped trend with altitude, while saturation of throat colouration linearly increased with elevation. These discrepant patterns are hard to explain on the only basis of altitudinal variation in sexual selection pressure. Moreover, altitudinal colour variation was similar in males and females, supporting the idea that it is provoked by natural selection, not by sexual selection [71]. Our findings contrast with those reported for a population of the western clade in central Spain, where P. algirus lizards have less saturated throats at higher altitude [29,30]. In our study population, lizard throat was darker at high elevations, which has also been reported in other lizard species [28,32]. Darker colouration with ascending elevation is a likely consequence of high dermal melanin [59].

This pattern of altitudinal variation in lizard colour signals and, especially, why eyespots and throat colouration covaried differently with elevation, requires an explanation in which both colour signals are differentially affected by selective pressures. Blue eyespots are structural colourations, mainly produced by the combination of a thick and well-arranged layer of iridophores and basal eumelanin. Meanwhile, yellow and orange colourations are produced by pigments such as carotenoids and pterins. We discuss several hypotheses that could explain the altitudinal patterns reported.

(1) Population density might affect the investment in social communication. In more densely populated zones, social encounters should be more frequent, conducing to increased contests. Given that colour signals in P. algirus apparently inform about fighting ability, one could expect more investment in social signals in zones with denser populations. However, this hypothesis is not supported, as density was maximal at mid-elevation, and minimal at lowlands [44], where the number of eyespots was the highest. Therefore, altitudinal variation in population density did not covary with either variation in the number of eyespots or throat saturation.

(2) We could also expect a trade-off between investment in signals and in self-maintenance [2]. Therefore, in zones where lizards invest more in longevity, social signals are expected to be less expressed (i.e., the pattern of longevity and signal intensity should be inverse). This hypothesis was not supported either, as longevity followed a U-shape with altitude [72], hence showing a pattern not consistent with a trade-off between self-maintenance and investment in colouration. Eyespots also followed a U-shaped pattern and throat colouration increased with elevation.

(3) Temperature is the main environmental factor that varies with elevation. Colder temperatures at higher elevations may limit activity, especially for ectotherms $[44,73]$. Moreover, elevated temperatures may favour sexual selection [74]. Although this 
could partially explain the highest number of eyespots at low elevations, hardly could it explain why investment in throat colouration increases with ascending altitude.

(4) Several colour traits in lizards are sensitive to parasites [36,75-80]. However, parasites follow a complex pattern with altitude in our study system, mite abundance decreasing, while haemoparasites prevalence increases, with ascending altitude [81]. Still, different types of colouration may be related to different types of parasites [82].

(5) Food availability increases with elevation in our study population [83]. Chromatic properties of lizard skin correlate with pigment density, highly saturated colour patches having more pigment density than paler and duller ones [84]. Therefore, if throat pigment concentration depends on food (e.g., if they are carotenoid-dependent), the increase in food availability could explain the highest investment in throat colouration with altitude $[85,86]$. The altitudinal pattern for eyespots would be different as structural colour are presumed to be less affected by food availability.

(6) Lizards at higher elevations suffer less oxidative damage than low-elevation ones $[87,88]$. Although we do not know if the yellow colouration in the throat is mediated by carotenoids or by pterins, both pigments may have antioxidant properties mainly mediated throughout a regulatory effect on the immune system [89]. Therefore, lizards from a higher elevation, exposed to a less oxidant ambient, could invest more in pigment-mediated social signals [90]. Meanwhile, the structural colouration of blue eyespots could be unaffected by oxidative stress.

(7) Altitudinal variation in female preferences for different colour traits in males could explain altitudinal variation in colouration [91] (also see [92,93]). However, this would hardly explain the low sexual dichromatism along the altitudinal gradient [71].

(8) The efficiency of colour signals depends on the context where the visual stimulus is produced, as environmental conditions also affect the dispersion of the signal [94]. Blue-ultraviolet colours (short wavelengths) are more effective in partially covered habitats, while yellow-orange colourations are more effective in open areas [94]. Low elevation sites, where eyespots are more numerous, are composed of Mediterranean forests, with low arboreal cover, loose bushes, and a matrix of open and forestry zones. In this type of habitat, short-length colours would be favoured. Meanwhile, high elevation sites are above the treeline, with a habitat composed of short and compact scrubs. In these sites, by contrast, yellow colouration might be favoured.

\subsection{Comparison with the Western Clade}

In the western clade, testosterone produces orange heads in adult males, but only an orange commissure in young males [38]. To produce or have an orange head is costly, as coloured individuals are more implied in fights, and colouration increases parasite susceptibility and reduces survival $[30,35,36,41]$. Why do males in the eastern clade not have orange heads during the breeding season? One possibility is paedomorphism, if adult lizards are retaining their youthful characteristics. This may occur because environmental conditions in the zones inhabited by the eastern clade favour an augment in the costs and/or decrease in the benefits associated with orange colouration. In the western clade, highly coloured males have larger home ranges that overlap with more females and so are more successful in mate acquisition [35,37,41]. The eastern clade inhabits more arid zones, with less plant cover and probably less food availability [42,95]. This might influence the social behaviour of this lizard (which is unstudied in the eastern clade), needing larger territories in which the control of several female territories is more difficult, and the contact with other males is rarer. Therefore, both intra- and intersexual selection could be lower in the eastern clade and so the benefits of an orange head could decrease. It is also possible that lizards in the eastern clade are more exposed to predators, given that they live in an opener environment [95]. Higher risk of predation would select against colourful males [96]. These questions remain open and show that $P$. algirus lizards offer a valuable opportunity to study and understand the evolution of nuptial colouration in lizards. 
Author Contributions: Conceptualization, G.M.-R.; methodology, G.M.-R., S.R. and M.C.; resources: G.M.-R.; investigation: S.R., F.J.Z.-C. and M.C.; data curation: S.R., M.C. and G.M.-R.; formal analysis, G.M.-R. and S.R.; writing, original draft, G.M.-R. and S.R.; writing, additional inputs, F.J.Z.-C. and M.C.; supervision, G.M.-R.; project administration, G.M.-R.; funding acquisition, G.M.-R. All authors have read and agreed to the published version of the manuscript.

Funding: This work was funded by the Spanish government (Ministerio de Ciencia e Innovación) with funds from the European Union (project CGL2009-13185). FJZC (AP2009-3505) and SR (AP20091325) were supported by two pre-doctoral grants from the Ministerio de Ciencia e Innovación (FPU programme).

Institutional Review Board Statement: The research was conducted under both Junta de Andalucía and National Park of Sierra Nevada research permits (references GMN/GyB/JMIF, ENSN/JSG/JEGT/MCF, $\mathrm{ENSN} / \mathrm{JSG} / \mathrm{BRL} / \mathrm{MCF}, \mathrm{SGMN} / \mathrm{GyB} / \mathrm{JMIF}$, and SSA/SI/MD/ps) issued to the authors.

Informed Consent Statement: Not applicable.

Data Availability Statement: The data presented in this study are openly available in FigShare at https:/ / doi.org/10.6084/m9.figshare.14376698.v1, accessed on 6 April 2021.

Acknowledgments: We thank the personnel from the Espacio Natural de Sierra Nevada for their constant support.

Conflicts of Interest: The authors declare no conflict of interest.

\section{Appendix A}

Table A1. Sample sizes per sex (males I females) and per altitude for each variable.

\begin{tabular}{cccccccc}
\hline & $\mathbf{3 0 0}$ & $\mathbf{7 0 0}$ & $\mathbf{1 2 0 0}$ & $\mathbf{1 7 0 0}$ & $\mathbf{2 2 0 0}$ & $\mathbf{2 5 0 0}$ & Total \\
\hline SVL & $61 \mid 45$ & $20 \mid 36$ & $19 \mid 30$ & $37 \mid 36$ & $42 \mid 50$ & $60 \mid 46$ & 482 \\
Body Mass & $59 \mid 44$ & $20 \mid 34$ & $18 \mid 30$ & $36 \mid 36$ & $42 \mid 50$ & $60 \mid 46$ & 475 \\
Head Width & $60 \mid 43$ & $19 \mid 29$ & $16 \mid 29$ & $37 \mid 33$ & $39 \mid 48$ & $57 \mid 45$ & 460 \\
Age & $11 \mid 12$ & $8 \mid 11$ & $10 \mid 10$ & $10 \mid 9$ & $9 \mid 7$ & $11 \mid 10$ & 118 \\
Eyespots & $44 \mid 28$ & $19 \mid 29$ & $16 \mid 23$ & $37 \mid 32$ & $32 \mid 37$ & $43 \mid 31$ & 371 \\
Throat Colour (LCH) & $59 \mid 45$ & $19 \mid 35$ & $17 \mid 30$ & $36 \mid 35$ & $42 \mid 49$ & $60 \mid 46$ & 473 \\
Commissure Patch Colour & $33 \mid 22$ & $11 \mid 15$ & $14 \mid 19$ & $32 \mid 25$ & $27 \mid 24$ & $35 \mid 24$ & 281 \\
Commissure Patch Size & $16 \mid 1$ & $5 \mid 2$ & $5 \mid 2$ & $20 \mid 6$ & $18 \mid 5$ & $25 \mid 9$ & 114 \\
\hline
\end{tabular}

\section{Appendix B}

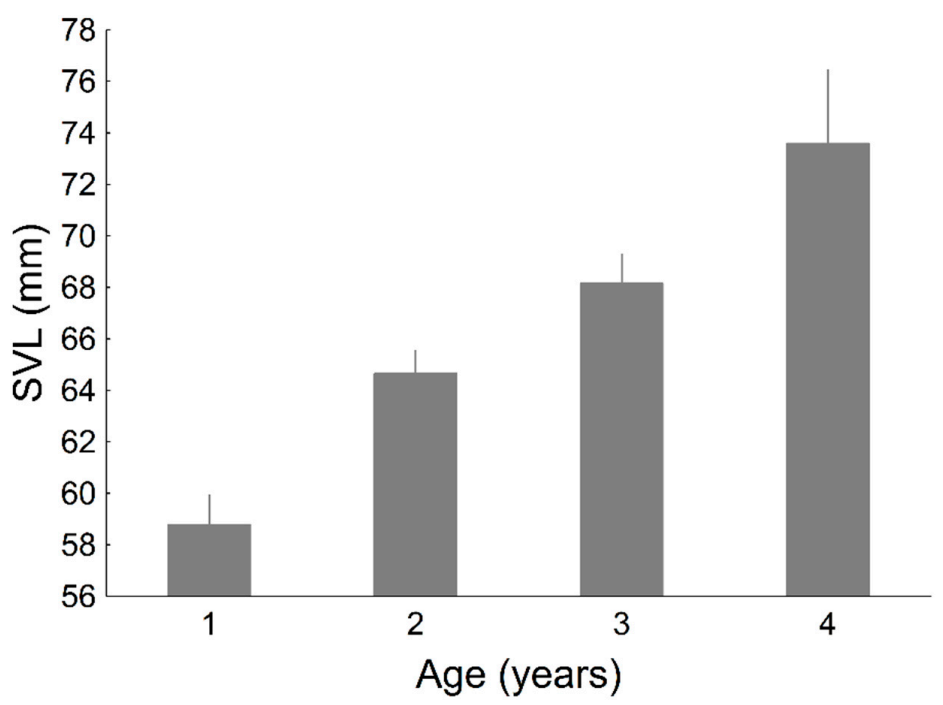

Figure A1. Average snout-vent length (SVL) of P. algirus lizards according to age estimated with skeletochronology. Lines indicate the starndard error. 


\section{References}

1. Bradbury, J.W.; Vehrencamp, S.L. Principles of Animal Communication; Sinauer: Sunderland, MA, USA, 2011.

2. Andersson, M. Sexual Selection; Princeton University Press: Princeton, NJ, USA, 1994.

3. Stevens, M.; Merilaita, S. (Eds.) Animal Camouflage: Mechanisms and Function; Cambridge University Press: Cambridge, UK, 2011.

4. Pérez i de Lanuza, G.; Font, E. The evolution of colour pattern complexity: Selection for conspicuousness favours contrasting within-body colour combinations in lizards. J. Evol. Biol. 2016, 29, 942-951. [CrossRef]

5. Andersson, S.; Pryke, S.R.; Örnborg, J.; Lawes, M.J.; Andersson, M. Multiple receivers, multiple ornaments, and a trade-off between agonistic and epigamic signaling in a widowbird. Am. Nat. 2002, 160, 683-691. [CrossRef]

6. Candolin, U. The use of multiple cues in mate choice. Biol. Rev. 2003, 78, 575-595. [CrossRef] [PubMed]

7. Martín, J.; López, P. Multiple color signals may reveal multiple messages in male Schreiber's green lizards, Lacerta schreiberi. Behav. Ecol. Sociobiol. 2009, 63, 1743-1755. [CrossRef]

8. Plasman, M.; Reynoso, V.H.; Nicolás, L.; Torres, R. Multiple colour traits signal performance and immune response in the Dickerson's collared lizard Crotaphytus dickersonae. Behav. Ecol. Sociobiol. 2015, 69, 765-775. [CrossRef]

9. Zamora-Camacho, F.J.; Comas, M. Beyond sexual dimorphism and habitat boundaries: Coloration correlates with morphology, age, and locomotor performance in a toad. Evol. Biol. 2019, 46, 60-70. [CrossRef]

10. Møller, A.P.; Pomiankowski, A. Why birds got multiple ornaments? Behav. Ecol. Sociobiol. 1993, 32, 167-176. [CrossRef]

11. Johnstone, R.A. Multiple displays in animal communication: "Backup signals" and "multiple messages". Philos. Trans. R. Soc. B 1996, 351, 329-338.

12. Grether, G.F.; Kolluru, G.R.; Nersissian, K. Individual colour patches as multicomponent signals. Biol. Rev. 2004, 79, 583-610. [CrossRef]

13. Olsson, M.; Stuart-Fox, D.; Ballen, C. Genetics and evolution of colour patterns in reptiles. Semin. Cell Dev. Biol. 2013, 24, 529-541. [CrossRef] [PubMed]

14. Olsson, M. Nuptial colouration in the sand lizard, Lacerta agilis: An intra-sexually selected cue to fighting ability. Anim. Behav. 1994, 48, 607-613. [CrossRef]

15. Whiting, M.J.; Stuart-Fox, D.M.; O'Connor, D.; Firth, D.; Bennett, N.C.; Blomberg, S.P. Ultraviolet signals ultra-aggression in a lizard. Anim. Behav. 2006, 72, 353-363. [CrossRef]

16. Bajer, K.; Molnár, O.; Török, J.; Herczeg, G. Ultraviolet nuptial colour determines fight success in male European green lizards (Lacerta viridis). Biol. Lett. 2011, 7, 866-868. [CrossRef] [PubMed]

17. Baird, T.A. Reproductive coloration in female collared lizards, Crotophytus collaris, stimulates courtship by males. Herpetologica 2004, 60, 337-348. [CrossRef]

18. Salica, M.J.; Halloy, M. Nuptial coloration in female Liolaemus quilmes (Iguania: Liolaemidae): Relation to reproductive state. Rev. Esp. Herpetol. 2009, 23, 141-149.

19. Stuart-Fox, D.; Goode, J.L. Female ornamentation influences male courtship investment in a lizard. Front. Ecol. Evol. 2014, 2, 2. [CrossRef]

20. Díaz, J.A.; Alonso-Gomez, A.L.; Delgado, M.J. Seasonal variation of gonadal development, sexual steroids, and lipid reserves in a population of the lizard Psammodromus algirus. J. Herpetol. 1994, 28, 199-205. [CrossRef]

21. Hews, D.K.; Moore, M.C. Influence of androgens on differentiation of secondary sex characters in tree lizards, Urosaurus ornatus. Gen. Comp. Endocrinol. 1995, 97, 86-102. [CrossRef]

22. Cox, R.M.; Zilberman, V.; John-Alder, H.B. Testosterone stimulates the expression of a social color signal in Yarrow's Spiny Lizard, Sceloporus jarrovii. J. Exp. Zool. A 2008, 309, 505-514. [CrossRef]

23. Macedonia, J.M. Habitat light, colour variation, and ultraviolet reflectance in the Grand Cayman anole, Anolis conspersus. Biol. J. Linn. Soc. 2001, 73, 299-320. [CrossRef]

24. Pérez i de Lanuza, G.; Carretero, M.A.; Font, E. Intensity of male-male competition predicts morph diversity in a color polymorphic lizard. Evolution 2017, 71, 1832-1840. [CrossRef]

25. Moreno-Rueda, G.; González-Granda, L.G.; Reguera, S.; Zamora-Camacho, F.J.; Melero, E. Crypsis decreases with elevation in a lizard. Diversity 2019, 11, 236. [CrossRef]

26. Keller, I.; Alexander, J.M.; Holderegger, R.; Edwards, P.J. Widespread phenotypic and genetic divergence along altitudinal gradients in animals. J. Evol. Biol. 2013, 26, 2527-2543. [CrossRef] [PubMed]

27. Badyaev, A.V. Altitudinal variation in sexual dimorphism: A new pattern and alternative hypotheses. Behav. Ecol. 1997, 8, 675-690. [CrossRef]

28. Leaché, A.D.; Helmer, D.-S.; Moritz, C. Phenotypic evolution in high-elevation populations of western fencce lizards (Sceloporus occidentalis) in the Sierra Nevada Mountains. Biol. J. Linn. Soc. 2010, 100, 630-641. [CrossRef]

29. Iraeta, P.; Monasterio, C.; Salvador, A.; Díaz, J.A. Sexual dimorphism and interpopulation differences in lizard hind limb length: Locomotor performance or chemical signalling? Biol. J. Linn. Soc. 2011, 104, 318-329. [CrossRef]

30. Llanos-Garrido, A.; Díaz, J.A.; Pérez-Rodríguez, A.; Arriero, E. Variation in male ornaments in two lizard populations with contrasting parasite loads. J. Zool. 2017, 303, 218-225. [CrossRef]

31. Martín, J.; Zamora-Camacho, F.J.; Reguera, S.; López, P.; Moreno-Rueda, G. Variations in chemical sexual signals of Psammodromus algirus lizards along an elevation gradient may reflect altitudinal variation in microclimatic conditions. Sci. Nat. 2017, 104, 16. [CrossRef] 
32. Ortega, J.; Martín, J.; Crochet, P.-A.; López, P.; Clobert, J. Seasonal and interpopulational phenotypic variation in morphology and sexual signals of Podarcis liolepis lizards. PLOS ONE 2019, 14, e211686. [CrossRef]

33. Salvador, A. Lagartija colilarga-Psammodromus algirus (Linnaeus, 1758). In Enciclopedia Virtual de los Vertebrados Españoles; Salvador, A., Marco, A., Eds.; Museo Nacional de Ciencias Naturales: Madrid, Spain, 2015.

34. Carranza, S.; Harris, D.J.; Arnold, E.N.; Batista, V.; Gonzalez De La Vega, J.P. Phylogeography of the lacertid lizard, Psammodromus algirus, in Iberia and across the Strait of Gibraltar. J. Biogeogr. 2006, 33, 1279-1288. [CrossRef]

35. Díaz, J.A. Breeding coloration, mating opportunities, activity, and survival in the lacertid lizard Psammodromus algirus. Can. J. Zool. 1993, 71, 1104-1110. [CrossRef]

36. Salvador, A.; Veiga, J.P.; Martín, J.; López, P.; Abelenda, M.; Puerta, M. The cost of producing a sexual signal: Testosterone increases the susceptibitily of male lizards to ectoparasitic infestation. Behav. Ecol. 1996, 7, 145-150. [CrossRef]

37. Salvador, A.; Veiga, J.P. Male traits and pairing success in the lizard Psammodromus algirus. Herpetologica 2001, 57, 77-86.

38. Salvador, A.; Veiga, J.P.; Martín, J.; López, P. Testosterone supplementation in subordinate, small male lizards: Consequences for aggressiveness, color development, and parasite load. Behav. Ecol. 1997, 8, 135-139. [CrossRef]

39. Carretero, M.A. Sources of colour pattern variation in Mediterranean Psammodromus algirus. Neth. J. Zool. 2002, 52, 43-60. [CrossRef]

40. Salvador, A.; Veiga, J.P. A permanent signal related to male pairing success and survival in the lizard Psammodromus algirus. Amphibia Reptilia 2008, 29, 117-120.

41. Martín, J.; Forsman, A. Social costs and development of nuptial coloration in male Psammodromus algirus lizards: An experiment. Behav. Ecol. 1999, 10, 396-400. [CrossRef]

42. Díaz, J.A.; Iraeta, P.; Verdú-Ricoy, J.; Siliceo, I.; Salvador, A. Intraspecific variation of reproduction traits in a Mediterranean lizard: Clutch, population, and lineage effects. Evol. Biol. 2012, 39, 106-115. [CrossRef]

43. Brooks, R.C.; Kemp, D.J. Can older males deliver the good genes? Trends Ecol. Evol. 2001, 16, 308-313. [CrossRef]

44. Zamora-Camacho, F.J.; Reguera, S.; Moreno-Rueda, G.; Pleguezuelos, J.M. Patterns of seasonal activity in a Mediterranean lizard along a 2200m altitudinal gradient. J. Thermal Biol. 2013, 38, 64-69. [CrossRef]

45. Zamora-Camacho, F.J.; Reguera, S.; Moreno-Rueda, G. Bergmann's Rule rules body size in an ectotherm: Heat conservation in a lizard along a 2200-metre elevational gradient. J. Evol. Biol. 2014, 27, 2820-2828. [CrossRef] [PubMed]

46. Perry, G.; Wallace, M.C.; Perry, D.; Curzer, H.; Muhlberger, P. Toe clipping of amphibians and reptiles: Science, ethics, and the law. J. Herpetol. 2011, 45, 547-555. [CrossRef]

47. Comas, M.; Reguera, S.; Zamora-Camacho, F.J.; Salvadó, H.; Moreno-Rueda, G. Comparison of the effectiveness of phalanges vs. humeri and femurs to estimate lizard age with skeletochronology. Anim. Biodiv. Conserv. 2016, 39, 237-240. [CrossRef]

48. Zhao, M.; Klaassen, C.A.J.; Lisovski, S.; Klaassen, M. The adequacy of aging techniques in vertebrates for rapid estimation of population mortality rates from age distributions. Ecol. Evol. 2019, 9, 1394-1402. [CrossRef]

49. Andersson, S.; Prager, M. Quantifying colors. In Bird Coloration. Vol. II: Function and Evolution; Hill, G.E., McGraw, K.J., Eds.; Harvard University Press: Boston, MA, USA, 2006; pp. 41-89.

50. Montgomerie, R. Analazing colors. In Bird Coloration. Vol. I: Mechanisms and Measurements; Hill, G.E., McGraw, K.J., Eds.; Harvard University Press: Boston, MA, USA, 2006; pp. 90-147.

51. Endler, J.A. On the measurement and classification of colour in studies of animal colour patterns. Biol. J. Linn. Soc. 1990, 41, 315-352. [CrossRef]

52. Rasband, W.S. Image]; US National Institutes of Health: Bethesda, MD, USA, 2008.

53. Zuur, A.F.; Ieno, E.N.; Elphick, C.S. A protocol for data exploration to avoid common statistical problems. Methods Ecol. Evol. 2010, 1, 3-14. [CrossRef]

54. Packard, G.C. Is logarithmic transformation necessary in allometry? Biol. J. Linn. Soc. 2013, 109, 476-486. [CrossRef]

55. R Development Core Team. R: A Language and Environment for Statistical Computing; R Foundation for Statistical Computing: Vienna, Austria, 2019.

56. Ripley, B.; Venables, W. nnet: Feed-Forward Neural Networks and Multinomial Log-Linear Models; R Foundation for Statistical Computing: Vienna, Austria, 2020.

57. Bartoń, K. MuMIn: Multi-Model Inference; R Foundation for Statistical Computing: Vienna, Austria, 2020.

58. Quinn, G.P.; Keough, M.J. Experimental Design and Data Analysis for Biologists; Cambridge University Press: Cambridge, UK, 2002.

59. Reguera, S.; Zamora-Camacho, F.J.; Moreno-Rueda, G. The lizard Psammodromus algirus (Squamata: Lacertidae) is darker at high altitudes. Biol. J. Linn. Soc. 2014, 112, 132-141. [CrossRef]

60. Huyghe, K.; Vanhooydonck, B.; Scheers, H.; Molina-Borja, M.; van Damme, R. Morphology, performance and fighting capacity in male lizards, Gallotia galloti. Funct. Ecol. 2005, 19, 800-807. [CrossRef]

61. Stapley, J.; Whiting, M.J. Ultraviolet signals fighting ability in a lizard. Biol. Lett. 2006, 2, 169-172. [CrossRef]

62. Pérez i de Lanuza, G.; Carazo, P.; Font, E. Colours of quality: Structural (but not pigment) coloration informs about male quality in a polychromatic lizard. Anim. Behav. 2014, 90, 73-81. [CrossRef]

63. Hamilton, D.G.; Whiting, M.J.; Pryke, S.R. Fiery frills: Carotenoid-based coloration predicts contest success in frillneck lizards. Behav. Ecol. 2013, 24, 1138-1149. [CrossRef]

64. Møller, A.P. Social control of deception among status signalling house sparrows Passer domesticus. Behav. Ecol. Sociobiol. 1987, 20, 307-311. [CrossRef] 
65. Lappin, A.K.; Brandt, Y.; Husak, J.F.; Macedonia, J.M.; Kemp, D.J. Gaping displays reveal and amplify a mechanically based index of weapon performance. Am. Nat. 2006, 168, 100-113. [CrossRef] [PubMed]

66. Weiss, S.L. Female-specific color is a signal of quality in the striped plateau lizard (Sceloporus virgatus). Behav. Ecol. 2006, 17, 726-732. [CrossRef]

67. Lande, R. Sexual dimorphism, sexual selection, and adaptation in polygenic characters. Evolution 1980, 34, 292-305. [CrossRef]

68. López, P.; Martín, J.; Cuadrado, M. Chemosensory cues allow male lizards Psammodromus algirus to override visual concealment of sexual identity by satellite males. Behav. Ecol. Sociobiol. 2003, 54, 218-224. [CrossRef]

69. Searcy, W.A.; Nowicki, S. The Evolution of Animal Communication; Princeton University Press: Princeton, NJ, USA, 2005.

70. Martín, J.; López, P. Nuptial coloration and mate guarding affect escape decision of male lizards Psammodromus algirus. Ethology 1999, 105, 439-447. [CrossRef]

71. Dunn, P.O.; Armenta, J.K.; Whittingham, L.A. Natural and sexual selection act on different axes of variation in avian plumage color. Sci. Adv. 2015, 1, e1400155. [CrossRef] [PubMed]

72. Comas, M.; Reguera, S.; Zamora-Camacho, F.J.; Moreno-Rueda, G. Age structure of a lizard along an elevational gradient reveals nonlinear lifespan patterns with altitude. Curr. Zool. 2020, 142, 373-382. [CrossRef] [PubMed]

73. Zamora-Camacho, F.J.; Reguera, S.; Moreno-Rueda, G. Thermoregulation in the lizard Psammodromus algirus along a 2200-m elevational gradient in Sierra Nevada (Spain). Int. J. Biometeorol. 2016, 60, 687-697. [CrossRef] [PubMed]

74. Olsson, M.; Wapstra, E.; Schwartz, T.; Madsen, T.; Ujvari, B.; Uller, T. In hot pursuit: Fluctuating mating system and sexual selection in san lizards. Evolution 2011, 65, 574-583. [CrossRef] [PubMed]

75. Václav, R.; Prokop, P.; Fekiač, V. Expression of breeding coloration in European Green Lizards (Lacerta viridis): Variation with morphology and tick infestation. Can. J. Zool. 2007, 85, 1199-1206. [CrossRef]

76. Calisi, R.M.; Malone, J.H.; Hews, D.K. Female secondary coloration in the Mexican boulder spiny lizard is associated with nematode load. J. Zool. 2008, 276, 358-367. [CrossRef]

77. Martín, J.; Amo, L.; López, P. Parasites and health affect multiple sexual signals in male common wall lizards, Podarcis muralis Naturwissenschaften 2008, 95, 293-300. [CrossRef]

78. Megía-Palma, R.; Martínez, J.; Merino, S. A structural colour ornament correlates positively with parasite load and body condition in an insular lizard species. Sci. Nat. 2016, 103, 52. [CrossRef]

79. Megía-Palma, R.; Martínez, J.; Merino, S. Manipulation of parasite load induces significant changes in the structural-based throat color of male Iberian green lizards. Curr. Zool. 2018, 64, 293-302. [CrossRef]

80. Megía-Palma, R.; Paranjpe, D.; Reguera, S.; Martínez, J.; Cooper, R.D.; Blaimont, P.; Merino, S.; Sinervo, B. Multiple color patches and parasites in Sceloporus occidentalis: Differential relationships by sex and infection. Curr. Zool. 2018, 64, 703-711. [CrossRef]

81. Álvarez-Ruiz, L.; Megía-Palma, R.; Reguera, S.; Ruiz, S.; Zamora-Camacho, F.J.; Figuerola, J.; Moreno-Rueda, G. Opposed elevational variation in prevalence and intensity of endoparasites and their vectors in a lizard. Curr. Zool. 2018, 64, 197-204. [CrossRef]

82. Megía-Palma, R.; Martínez, J.; Merino, S. Structural- and carotenoid-based throat colour patches in males of Lacerta schreiberi reflect different parasitic diseases. Behav. Ecol. Sociobiol. 2016, 70, 2017-2025.

83. Moreno-Rueda, G.; Melero, E.; Reguera, S.; Zamora-Camacho, F.J.; Álvarez-Benito, I. Prey availability, prey selection, and trophic niche width in the lizard Psammodromus algirus along an elevational gradient. Curr. Zool. 2018, 64, 603-613. [CrossRef] [PubMed]

84. Cuervo, J.J.; Belliure, J.; Negro, J.J. Coloration reflects skin pterin concentration in a red-tailed lizard. Comp. Biochem. Physiol. B 2016, 193, 17-24. [CrossRef]

85. Hill, G.E. Geographic variation in the carotenoid plumage pigmentation of male house finches (Carpodacus mexicanus). Biol. J. Linn. Soc. 1993, 49, 63-86. [CrossRef]

86. Grether, G.F.; Hudon, J.; Millie, D.F. Carotenoid limitation of sexual coloration along an environmental gradient in guppies. Proc. R. Soc. B 1999, 266, 1317-1322. [CrossRef]

87. Reguera, S.; Zamora-Camacho, F.J.; Trenzado, C.E.; Sanz, A.; Moreno-Rueda, G. Oxidative stress decreases with elevation in the lizard Psammodromus algirus. Comp. Biochem. Physiol. A 2014, 172, 52-56. [CrossRef]

88. Reguera, S.; Zamora-Camacho, F.J.; Melero, E.; García-Mesa, S.; Trenzado, C.E.; Cabrerizo, M.J.; Sanz, A.; Moreno-Rueda, G. Ultraviolet radiation does not increase oxidative stress in the lizard Psammodromus algirus along an elevational gradient. Comp. Biochem. Physiol. A 2015, 183, 20-26. [CrossRef]

89. McGraw, K.J. The antioxidant function of many animal pigments: Are there consistent health benefits of sexually selected colourants? Anim. Behav. 2005, 69, 757-764. [CrossRef]

90. Olsson, M.; Tobler, M.; Healey, M.; Perrin, C.; Wilson, M. A significant component of ageing (DNA damage) is reflected in fading breeding colors: An experimental test using innate antioxidant mimetics in painted dragon lizards. Evolution 2012, 66, 2475-2483. [CrossRef]

91. Jennions, M.D.; Petrie, M. Variation in mate choice and mating preferences: A review of causes and consequences. Biol. Rev. 1997, 72, 283-327. [CrossRef]

92. Brooks, R.C.; Couldridge, V. Multiple sexual ornaments coevolve with multiple mating preferences. Am. Nat. 1999, 154, 37-45. [CrossRef]

93. Kwiatkowski, M.A.; Sullivan, B.K. Geographic variation in sexual selection among populations of an iguanid lizard, Sauromalus obesus (=ater). Evolution 2002, 56, 2039-2051. [CrossRef] [PubMed] 
94. Endler, J.A. The color of light in forests and its implications. Ecol. Monogr. 1993, 63, 1-27. [CrossRef]

95. Díaz, J.A.; Verdú-Ricoy, J.; Iraeta, P.; Llanos-Garrido, A.; Pérez-Rodríguez, A.; Salvador, A. There is more to the picture than meets the eye: Adaptation for crypsis blurs phylogeographical structure in a lizard. J. Biogeogr. 2017, 44, 397-408. [CrossRef]

96. Stuart-Fox, D.M.; Moussalli, A.; Marshall, N.J.; Owens, I.P.F. Conspicuous males suffer higher predation risk: Visual modelling and experimental evidence from lizards. Anim. Behav. 2003, 66, 541-550. [CrossRef] 